\title{
Giro rural y memorias del conflicto armado en la novela colombiana del siglo XXI
}

\section{Rural Turn and Memories of the Armed Conflict in the Colombian Novel of the XXI Century}

\begin{abstract}
Resumen
El desarrollo conceptual de la memoria muestra la necesidad de construir relatos que afronten el duelo sin desactivar su potencia política. Para esto, siguiendo a Rancière y a Agamben, es preciso promover el disenso haciendo visibles las "partes sin-parte" del cuerpo social y las fisuras del presente, lo que se puede percibir en narraciones del "giro rural", una tendencia cada vez mayor en la literatura latinoamericana. En el caso de Colombia, este desplazamiento, estrechamente vinculado con la construcción de memorias del conflicto armado, reivindica relatos soslayados por los principales discursos sobre la violencia, como el daño a los ecosistemas y el despojo de territorios campesinos y ancestrales. Para determinar la relación entre las memorias del conflicto armado y el giro rural, analizo dos novelas: Los derrotados, de Pablo Montoya, y Elástico de sombra, de Juan Cárdenas. A partir de las similitudes y diferencias entre ambas, esbozaré al final algunas líneas generales sobre el giro rural y su importancia en la literatura actual.
\end{abstract}

Palabras claves Giro rural, memoria del conflicto armado, novela colombiana del siglo XXI, Pablo Montoya, Juan Cárdenas.

\begin{abstract}
The conceptual development of memory shows the need of constructing stories that confront grief without deactivating its political power. For this, following Rancière and Agamben, it's necessary to promote dissent by making visible the "parts with no part" of the social body and the fissures of the present, which can be seen in some narratives of the "rural turn", a growing
\end{abstract}


trend in Latin American literature. In the case of Colombia, this displacement, closely linked to the construction of memories of the armed conflict, vindicates stories that have been ignored by the main discourses about violence, such as damage to ecosystems and the dispossession of peasant and ancestral territories. In order to determine the relationship between the memories of the armed conflict and the rural turn, I analyze two novels: Los derrotados, by Pablo Montoya, and Elástico de sombra, by Juan Cárdenas. Starting from the similarities and differences between the two, I will outline at the end some general lines about the rural turn and its importance in current literature.

Keywords Rural turn, memory of the armed conflict, Colombian novel of the XXI century, Pablo Montoya, Juan Cárdenas.

\section{Introducción}

A diferencia de lo sucedido en la mayoría de países latinoamericanos, en Colombia, por varias décadas, se ha venido haciendo una "memoria del presente". Incluso hoy, después de cuatro años de la firma del Acuerdo de Paz estamos lejos de asegurar la desaparición de las dinámicas del conflicto armado. Así lo demuestran las masacres recientes, los asesinatos selectivos de líderes sociales, los enfrentamientos del Ejército con el ELN y las disidencias de las FARC. Estos y otros hechos manifiestan la pervivencia de "viejos" mecanismos en formas de violencia que tampoco son del todo nuevas. Ante tal complejidad, ante la dificultad de concluir este trauma colectivo, ¿qué papel debe interpretar la memoria?, ¿cómo evitar que el recuerdo doloroso del ayer soslaye las acciones urgentes que reclaman las injusticias del hoy?, ¿cómo no paralizarse ante el horror y seguir luchando?, ¿cómo conseguir, en últimas, que la literatura no se hunda en las arenas movedizas del pesimismo y pueda contestar a las condiciones estructurales que desencadenan, una y otra vez, la violencia?

Varios aportes de la sociología y la crítica literaria en América Latina insisten en la necesidad de que la memoria mantenga vivas, en el presente, las potencias del pasado; que no caiga en la tentación, por referirse a un dolor pretérito, de ser inofensiva en el ahora. Para comprender este punto, fijémonos brevemente en la evolución sociológica del concepto de "memoria" remontándonos al trabajo 
de Maurice Halbwachs, un pionero en el desarrollo de la noción de "memoria colectiva”, con la cual el autor quería demostrar que siempre hay un fundamento social en los recuerdos: "Nunca estamos solos", explica Halbwachs siguiendo el paradigma durkheimiano, "[y] no debemos olvidar que nuestros sentimientos y pensamientos más íntimos se originan en entornos y circunstancias sociales definidos" (36). Esto significaría que, incluso en soledad, el individuo está atravesado por la sociedad. Tal premisa cobra sentido si se tienen en cuenta que, para Halbwachs, el objetivo era demostrar que la memoria cumple un papel esencial en la cohesión social. No obstante, lo anterior contrasta con el énfasis que hacen los estudios contemporáneos en las raíces traumáticas de la memoria y en su potencial reivindicativo y emancipatorio. Aleida Assmann, por ejemplo, tomando en cuenta la caída de los grandes relatos, el poscolonialismo, las luchas políticas de grupos históricamente marginados y la desaparición generacional de testigos directos de episodios como el Holocausto o las dictaduras latinoamericanas, ha manifestado que la memoria, si bien es fundamental para la existencia de cualquier grupo humano, también tiene la capacidad de producir y mantener la tensión política, incluso en las sociedades aparentemente más homogéneas. En esta misma vía, Astrid Erll ha postulado la noción de "culturas del recuerdo" para resaltar que "en cada sociedad hay [...] una variedad de comunidades del recuerdo que coexisten y que, a menudo, compiten entre sí” (141). Ha habido, entonces, una ampliación del concepto de memoria que reconoce, además de su capacidad cohesionadora, su potencial político ${ }^{1}$.

¿Pero qué es lo político? Para Jacques Rancière, la política se define por el desacuerdo. De hecho, cuando solo hay consenso, cuando todas las partes que componen la comunidad ocupan un lugar predeterminado (unos visibles y otros no visibles, es decir, unos con participación y otros sin ella), ya no hay política sino

${ }^{1}$ Con esto no quiero decir que la memoria colectiva postulada por Halbwachs carezca de una dimensión política; por el contrario, su esencia cohesionadora, como anotó Reyes Mate (156), debe leerse en el contexto de la Europa posterior a la Primera Guerra Mundial, en la que muchos intelectuales reclamaban unidad política para superar la crisis. 
policía $^{2}$. Así pues, si se trata de conservar la tensión política del desacuerdo, la memoria no puede ser única, sino plural y conflictiva. Debe haber, más precisamente, memorias que pongan en el terreno de lo visible relatos que hagan tambalear el orden del presente. En este sentido, podríamos trazar un vínculo con la noción de contemporaneidad, tal como la entiende Giorgio Agamben, para quien lo contemporáneo se relaciona con lo "intempestivo", palabra empleada por Nietzsche para criticar algo del tiempo propio que, en general, es motivo de orgullo. Así, lo contemporáneo se vincula con la inactualidad, el desajuste y el anacronismo para percibir mejor el presente. Esta actitud, que en nada se parece a la nostalgia, implica fijarse en las oscuridades del tiempo propio poniéndolo en relación con otros tiempos, es decir, siendo capaz "de leer de modo inédito la historia", para "responder a las tinieblas del ahora" (7). Vista de este modo, la memoria es una rearticulación de temporalidades: no supone una simple vuelta a lo que sucedió, sino una manera de referirse al hoy y a las posibilidades del mañana.

Desplazamientos conceptuales como los descritos han tenido un impacto fuerte en la crítica literaria que estudia la memoria en América Latina. No en vano, Idelber Avelar aborda el tema a partir de textos que él califica como "intempestivos" por reflejar el desecho, la ruina, la fractura y la incompletitud, es decir, por mostrar aquello que ha sido dejado atrás en el relato histórico y que, al exigir su restitución, rompe la totalidad simbólica sin renunciar a "la apertura absoluta del futuro" (191). Esta apertura también interesa a Nelly Richard, para quien la memoria debe oponerse al olvido y al silenciamiento promovido por el consenso $^{3}$. Bajo este punto de vista, para conservar su fuerza, la memoria debe

${ }^{2}$ Dice Rancière: "La policía es primeramente un orden de los cuerpos que define las divisiones entre los modos del hacer, los modos del ser y los modos del decir, que hace que tales cuerpos sean asignados por su nombre a tal lugar y a tal tarea; es un orden de lo visible y lo decible que hace que tal actividad sea visible y tal otra no lo sea, que tal palabra sea entendida como perteneciente al discurso y tal otra al ruido" (El desacuerdo 44).

${ }^{3}$ Rancière define el consenso como "un modo de estructuración simbólica de la comunidad que abandona el núcleo político que lo constituye: el disenso" (El giro ético 236). Richard se opone también a esta figura que opera, no con una represión evidente, sino con un juego de apariencias que echa mano de la unanimidad institucional. 
superar la clausura que representan la melancolía ${ }^{4}$ y la deslegitimación de los antagonismos políticos.

¿Pero cómo logra la literatura, en el caso del conflicto armado, afrontar esta tarea? ¿Cómo entra en contacto de otra manera con el pasado para mantener activas sus fuerzas? A partir de estas preguntas, analizo aquí dos novelas colombianas: Los derrotados (2012), de Pablo Montoya, y Elástico de sombra (2019), de Juan Cárdenas. La primera se sitúa parcialmente en el espacio rural, mientras que la segunda lo hace totalmente. Este hecho, clave para la tesis doctoral que estoy desarrollando, no solo da cuenta de una de las maneras "disidentes" en que se construyen memorias del conflicto armado en Colombia, sino también de un "giro" reciente en la literatura latinoamericana que evidencia la potencia política de la memoria, tal como he expuesto hasta aquí.

\section{El giro rural en América Latina y Colombia}

"Salir" de la ciudad para narrar espacios no metropolitanos, como pueblos, desiertos, selvas, etcétera, constituye un desplazamiento reciente que ha sido registrado por algunos investigadores. En el caso específico de lo rural, Vicente Luis Mora señala que esta tendencia (no exenta de cálculos comerciales en determinados casos) se manifiesta en diversas literaturas en lengua española. Así mismo, Lucía De Leone analiza esta veta en Argentina. No deja de ser curioso este "retorno" al campo local, más aún teniendo en cuenta la relevancia de discursos críticos y literarios que, a finales del siglo XX y principios del XXI, apuntaban a una literatura latinoamericana urbana e, incluso, extraterritorial. Esto se puede ilustrar con las proclamas literarias más difundidas en el cambio de siglo. En la

${ }^{4}$ En términos freudianos, el trauma es el golpe que genera la pérdida. Dicha pérdida motiva el duelo, cuya irresolución da lugar a la melancolía, que impide la creación de sentido (Freud 239). Nelly Richard pone en relación estas nociones con el trabajo de Julia Kristeva para elaborar una crítica a la melancolía: "Según Kristeva, el efecto melancólico-depresivo proviene no solo de la tristeza dejada por la irrecuperabilidad de lo perdido, sino de una alteración destructiva de los nexos significantes que bloquea la capacidad de representar, es decir, de generar equivalencias simbólicas que transformen el síntoma de la pérdida en palabras e imágenes recreadoras de sentido" (172). 
introducción de $\mathrm{McOndo}$, firmada por los escritores chilenos Sergio Gómez y Alberto Fuguet, se juzgaba inmoral "vender" un continente rural cuando este era principalmente urbano, "sobrepoblado y lleno de contaminación, con autopistas, metro, TV-cable y barriadas [...] McDonald's, computadores Mac, condominios, amén de hoteles cinco estrellas construidos con dinero lavado y malls gigantescos" (15). Salvando las distancias entre McOndo y el Manifiesto Crack (Chávez y otros), en este último se pueden encontrar premisas similares en cuanto a lo rural, por ejemplo, en la diatriba de Ignacio Padilla contra el realismo mágico y en su reivindicación de una estética de la dislocación, que se cristaliza en obras que, como En busca de Klingsor (1999), de Jorge Volpi (integrante del Crack), no solo se sitúan en espacios urbanos, sino también extraterritoriales.

Estas tendencias urbanas y nomádicas en la literatura latinoamericana (Noguerol, Narrar; Aínsa) contrastan con la aparición, en los últimos años, de novelas que "retornan" a escenarios locales y rurales. Fruta podrida (2007), de Lina Meruane; Poso Wells (2007), de Gabriela Alemán; El espiritu de mis padres sigue subiendo en la lluvia (2011), de Patricio Pron; El mal de la taiga (2012), de Cristina Rivera Garza; Iris (2014), de Edmundo Paz-Soldán; Distancia de rescate (2014), de Samanta Schweblin; Las tierras arrasadas (2015), de Emiliano Monge; Ahora me rindo y eso es todo (2018), de Álvaro Enrigue; y Desierto sonoro (2019), de Valeria Luiselli, son algunos ejemplos de un listado cada vez mayor que podría incluir también películas como La ciénaga (2001), de Lucrecia Martel; La teta asustada (2009), de Claudia Llosa, y Ciudadano ilustre (2016), de Gastón Duprat y Mariano Cohn. La mención al cine no es gratuita. En Colombia, este giro hacia escenarios periféricos parece ser más fuerte (o, cuando menos, ha recibido mayor atención crítica) en este arte. Justamente, la investigadora María Ospina señala que, si bien los ámbitos urbanos siguen siendo centrales en la filmografía colombiana, también se puede apreciar un "rural turn" en un creciente número de producciones que localizan su acción en el campo o en la selva. Ejemplos de ello serían cintas como Los colores de la montaña (2010), La sirga (2013), La tierra y la sombra (2015) y El abrazo de la serpiente (2015), además de otras estrenadas después del 
ensayo de Ospina, como Pájaros de verano (2018) y Monos (2019). En las artes plásticas, también podríamos encontrar ejemplos como el trabajo de Juan Manuel Echavarría.

Sin embargo, esta misma vertiente ha recibido poca atención en la literatura colombiana, acaso por el énfasis urbano de las investigaciones del siglo XXI. De hecho, en el 2001, se publicaron dos trabajos que fijaban la mirada en la narración de la ciudad: La Generación Mutante, de Orlando Mejía Rivera, y Ciudades escritas, de Luz Mary Giraldo. Algo semejante se puede observar en trabajos más recientes, como Sitios de contienda (2010), de Juana Suárez, y Residuos de la violencia (2015), de Andrea Fanta Castro, en los cuales se analiza la relación violencia-literatura en Colombia por medio de corpus que seleccionan obras que transcurren total (o casi totalmente) en el espacio urbano, como La virgen de los sicarios (1994), de Fernando Vallejo; Perder es cuestión de método (1997), de Santiago Gamboa; Rosario Tijeras (1999), de Jorge Franco; Satanás (2002), de Mario Mendoza, y El olvido que seremos (2006), de Héctor Abad Faciolince. Una excepción importante la constituye La violencia y sus huellas (2011), de María Helena Rueda. Aunque en dicha investigación también se analiza la violencia colombiana contemporánea principalmente a partir de narraciones urbanas, como las ya citadas, y extraterritoriales, como El síndrome de Ulises (2005), de Santiago Gamboa, Rueda también estudia obras como las de Alfredo Molano y Los ejércitos (2007), de Evelio Rosero.

Precisamente, Los ejércitos podría considerarse un parteaguas dentro de las narraciones de la violencia en la Colombia del siglo XXI, en la que se había recurrido, sobre todo, a espacios urbanos y a estrategias como la autoficción. Sin embargo, después de Los ejércitos, aparecen más novelas que se ambientan en lo rural para narrar el conflicto armado desde una perspectiva diferente a la de los carteles urbanos de la droga ${ }^{5}$ : Libranos del bien (2008), de Alonso Sánchez Baute;

\footnotetext{
${ }^{5}$ Con esto no quiero decir que el narcotráfico esté ausente en las narraciones del giro rural (de hecho, está altamente presente el tema de los corredores de droga), ni quiero trazar una falsa dicotomía entre conflicto armado y narcotráfico. Se trata, en realidad, de un cambio de perspectiva: como es
} 
Abraham entre bandidos (2010), de Tomás González; Viaje al interior de una gota de sangre (2011) y Rebelión de los oficios inútiles (2014), de Daniel Ferreira; Tierra quemada (2013), de Óscar Collazos; El espantapájaros (2013) y Río muerto (2020), de Ricardo Silva Romero; La oculta (2014), de Héctor Abad Faciolince; Dime si en la cordillera sopla el viento (2015), de Samuel Jaramillo; Loveland (2017), de Luis Alfonso Salazar; Joaquina Centeno (2017), de Marbel Sandoval Ordóñez; Era más grande el muerto (2017), de Luis Miguel Rivas; Celebraciones (2019), de Leonardo Gil Gómez, y La sembradora de cuerpos (2019), de Philip Potdevin, son algunas de las obras que podrían enmarcarse en el giro rural colombiano, el cual se relaciona principalmente con la violencia del conflicto $\operatorname{armado}^{6}$.

La importancia de este giro rural en la discusión aquí planteada proviene de lo ético y lo estético. El campo no solo ha sido el principal escenario (y una gran víctima) de la violencia del conflicto armado; ha sido también un espacio soslayado por la vocación metropolitana de los principales discursos críticos y literarios de cambio de siglo. Se ha constituido, en términos rancerianos, como algo no visible, como una parte sin-parte que no tiene un papel activo dentro de lo común. Así mismo, en términos estéticos, podríamos identificar lo rural como lo faltante, y la falta ha sido una cuestión central en la estética moderna, desde precursores como Hegel, Adorno y Benjamin, hasta herederos próximos en el tiempo como el propio Rancière. De hecho, en la raíz de la estética moderna se encuentra la negatividad con sus posibilidades productivas, que emanan del carácter temporal de lo moderno en contraposición a la aspiración eterna de lo clásico (Prieto 15). Lo estético se

bien sabido, la mayor parte de la producción cultural nacional y foránea ha abordado el problema de la violencia reciente en Colombia a partir de la historia de carteles como el de Medellín y Cali, adoptando una perspectiva que Carlos Monsiváis denominó "narcocultura". Con este término, Monsiváis se refería a esa lectura, más difundida por la industria del espectáculo que por la historia o la academia, según la cual el narcotráfico era, esencialmente, una amalgama emocionante y kitsch de violencia, corrupción, venganzas, aventuras, dinero y mujeres.

${ }^{6}$ No obstante, también podríamos incluir en este giro obras anteriores a Los ejércitos, como La multitud de errante (2001), de Laura Restrepo, y Amor enemigo (2005), de Patricia Lara, así como novelas que no se vinculan de manera directa al conflicto armado, por ejemplo, La perra (2017), de Pilar Quintana; El diablo de las provincias (2017), de Juan Cárdenas, y Después de la ira (2018), de Cristián Romero. 
vincula así con lo ético, justamente visibilizando lo faltante, es decir, los cortes, las carencias y las fallas de legibilidad del cuerpo social. De esta manera, no podríamos entender el desplazamiento hacia los espacios rurales como un movimiento de carácter estrictamente territorial, sino también como una búsqueda ética y estética para leer el pasado de otras maneras, es decir, para producir memorias que denuncien las sombras del hoy y que abran nuevas perspectivas a futuro. Desde luego, no todas las obras que podrían incluirse dentro del giro rural tienen estas pretensiones. Sin embargo, una buena parte de ellas manifiesta este proyecto de manera más o menos explícita, como sucede en las dos novelas que analizaré a continuación.

\section{Los derrotados y la naturaleza}

Un elemento fundamental del campo es la naturaleza. No es de extrañar, entonces, que en algunas obras del giro rural se retome el tema de la aproximación a lo natural, muy importante en las novelas de la selva y de la tierra de principios y mediados del siglo XX. Estas, aunque criticaban fuertemente los discursos y las políticas sobre los recursos naturales, anticipando debates ecológicos de gran relevancia hoy, también reprodujeron la dicotomía naturaleza-ser humano y, por ende, deshistorizaron esos espacios naturales y a las comunidades que los habitan (Marcone 299). Esta objeción encuentra sustento en el aparato conceptual de la ecocrítica, para la cual, más que la representación, lo fundamental es la relación que los seres establecen con su entorno ${ }^{7}$.

\footnotetext{
${ }^{7}$ Para Cheryl Glotfelty, hay tres instancias en el desarrollo de la ecocrítica: la primera se ocupa de la representación de la naturaleza; la segunda, de la recuperación de obras relacionadas con la naturaleza, y la tercera, teórica y más compleja, de las construcciones simbólicas de las especies y su relación con el medio ambiente. Esto ha hecho que la noción de lugar vuelva a ser relevante (Heffes 12). Lo anterior, que ya se entreveía en las hipótesis de Raymond Williams en su clásico libro El campo y la ciudad, donde se afirma que el paisaje es un punto de vista antes que una construcción estética, coincide también con la emergencia del concepto sociológico de "nueva ruralidad", el cual se resiste a definir lo rural como lo opuesto de lo urbano (dicotomía anclada a asociaciones de uso común que indican que lo rural es agrario y atrasado, mientras que lo urbano es industrial y moderno), sumando categorías como el modo de vida de los habitantes del campo, su relación con el espacio y su capacidad de agencia (Matijasevic y Ruiz 26).
} 
Parto de este punto para analizar la construcción de memoria en Los derrotados. En esta novela, un escritor, Pedro Cadavid, recibe el encargo de redactar una biografía de Francisco José de Caldas. Mientras Pedro busca la información para elaborar ese texto, se topa con algunas cartas que, años atrás, le envió Santiago Hernández, un amigo suyo de la juventud que hizo parte de la guerrilla del EPL. Este encuentro con las cartas funciona como un "disparador" de la memoria que hace que la novela tenga, en total, tres hilos narrativos: el examen de la vida de Caldas, la historia de un grupo de amigos cuyas vidas están marcadas por el conflicto armado y la metanarración en la que Pedro reflexiona sobre su proyecto literario y la inclusión de material histórico en obras ficcionales. Es necesario destacar que, antes de la aparición de esta obra, Montoya solo había publicado novelas históricas extraterritoriales: me refiero a La sed del ojo (2004) y Lejos de Roma (2008). Con Los derrotados y el volumen de cuentos Adiós a los próceres, se inicia en la obra de este autor otra vertiente signada por la memoria en la Colombia contemporánea, rasgo que se acentuará en La escuela de música (2018) y La Escombrera ${ }^{8}$. Este "regreso" literario a lo local se discute de manera explícita en la obra: en una conversación con Santiago, Pedro, trasunto ficcional del propio Montoya, reflexiona sobre la "obligación" de los escritores colombianos de referirse a la violencia:

Claro que se puede escribir sobre otros asuntos [...] Una novela sobre la desnudez y el voyerismo, cuentos sobre música clásica, diarios de viaje a Europa, ensayos sobre artes plásticas, fotografía y botánica. Pero tarde o temprano te darás cuenta, si eres un escritor colombiano de verdad, que la realidad que nutre esas circunstancias, digamos íntimas, o subjetivas, o extraterritoriales, está urdida por la violencia. (145)

\footnotetext{
${ }^{8} \mathrm{Al}$ momento de escribir este ensayo, solo se han publicado algunos fragmentos de La Escombrera en la Revista Universidad de Antioquia: https://revistas.udea.edu.co/index.php/revistaudea/article/view/343721/20803639.
} 
Quien esté familiarizado con la literatura de Montoya notará rápidamente en este fragmento un examen de la obra anterior del autor, con guiños a novelas, poemas, cuentos y ensayos suyos. Este movimiento de regreso es fundamental como elemento constituyente del giro rural, que, como he dicho, abre la puerta en Los derrotados a una reflexión sobre la naturaleza americana. Esta aparece, principalmente, de dos maneras: por un lado, en el amor que siente Caldas hacia las plantas y las geografías de la Nueva Granada y, por el otro, en los escenarios rurales afectados por la violencia del conflicto armado. Ambas líneas contribuyen a establecer una relación entre naturaleza y violencia, que en la novela se considera a partir de una pregunta que se hace Pedro en sus notas para escribir la vida de Caldas: “¿Cómo desmitificar la naturaleza americana?”, es decir, ¿cómo no idealizarla poéticamente para desmontar esa "peligrosa construcción de la cultura" que es el "paraíso americano"? (172). Según nos sugiere la obra, el exotismo y el asombro esconden una realidad violenta, injusta, que no debe caer en el olvido. Si atendemos al epígrafe de Camus que utiliza la novela, "Si je veux écrire sur les hommes, ¿comment m'écarter du paysage?", para hacer memoria de la violencia colombiana, es necesario hablar también de la naturaleza; es necesario, por tanto, construir otros relatos que no reduzcan el presente a una desideologizada y ahistórica lucha armada entre los "buenos", que combaten del lado del Estado, y los "malos", que actúan desde la insurgencia. ¿Cómo hacerlo? Pensadores como Johan Galtung y, más recientemente, Slavoj Zizek, han insistido en la necesidad de trascender el análisis de la violencia como hecho físico, verificable mediante los sentidos, para desentrañar los mecanismos invisibles y estructurales que la producen y reproducen. Rastreando esa violencia estructural, Los derrotados se remonta hasta la Conquista para urdir un relato de dominación e injusticia que, desde un pasado lejano, problematiza el ahora. Así lo afirma Zapata, el profesor de Historia del Liceo Antioqueño, donde estudia el grupo de amigos: "Estamos atrapados en un engaño de siglos [...] que nos ha impedido ver los verdaderos motivos y las consecuencias de los acontecimientos", explica el docente; engaño que es "una clara expresión de quienes nos han gobernado desde que América fue 
invadida y colonizada por los europeos". Por tanto, más que una historia de descubridores, conquistadores y próceres, es necesario ver a esos personajes "como fichas de un movimiento social que se apoya en mecanismos de poder que, aunque muy claros, siempre pasan desapercibidos" (74).

En esta otra comprensión del pasado 9 , la naturaleza desempeña un papel fundamental. Es ella la que, en medio de su exuberancia aparentemente ahistórica, conserva, por cuenta del despojo y la explotación sucesiva, un rastro material de la larga violencia estructural:

Un hombre que se embelesa [con la naturaleza americana] desdeña, en medio de su borrachera lírica, el hecho de que a su lado haya un rastro de matanzas y fructuosos negocios bursátiles que han alimentado a lo largo de los siglos hordas de facinerosos. Primero fue el oro y la plata. Luego la caña de azúcar, el cacao, el tabaco y las quinas. Más tarde el caucho, el café, el banano. Ahora es la coca y la amapola. Después serán el agua, los biocombustibles, el litio. Los productos cambian, pero el mecanismo del despojo es el mismo. (173)

Este relato de sucesiva explotación permea toda la obra. Se dice de Peque, un pueblo situado entre la Serranía de Urama y el Nudo de Paramillo, que podría ser escenario de una utopía renacentista; en cambio, es uno de los pueblos más miserables de Antioquia. Puerto Valdivia, por su parte, se toma como paradigma de la larga explotación: el pueblo forma parte de un corredor por el que se contrabandeaba oro en la Colonia; hoy es la cocaína. Aldeas con nombres que el narrador juzga hermosos, como Napipí, Vigía del Fuerte, Bojayá y Jurado, son sinónimos de la desgracia por estar en un corredor de droga disputado por el Ejército, las guerrillas y los paramilitares. Así mismo, la historia de la orquídea, la

\footnotetext{
${ }^{9}$ En un ensayo anterior, en el que analizo Adiós a los próceres, explico cómo las libertades de la narrativa histórica, tal como las comprende Montoya, le permiten a este autor remontarse al pasado para elaborar críticas hacia el presente (Saldarriaga Gutiérrez, La búsqueda posnacional).
} 
flor nacional, es vista desde el saqueo y, por tanto, el narrador concluye que "nuestro símbolo es la belleza sostenida en el crimen. El exotismo oculto tras la voracidad del libre comercio y el laissez faire sin escrúpulos” (303-304).

Otro punto a destacar es la preocupación por el futuro ("el agua, los biocombustibles, el litio”). Es verdad que en la obra de Montoya predomina el desencanto. Los derrotados, de hecho, podría leerse como una historia que escenifica el tránsito del entusiasmo revolucionario al escepticismo. Sin embargo, y he aquí otro rasgo importante del giro rural en Colombia, esas memorias del conflicto armado desde periferias territoriales no siempre conducen a una parálisis. Hay, en Los derrotados y en otras novelas que forman parte de este giro, un llamado (por pequeño que pueda ser) a la acción. De esta manera, se rehace un vínculo de temporalidades cuya intensidad varía según cada obra, pero que contrasta con actitudes como el desencanto y el pesimismo que marcaron el cambio de siglo en América Latina ${ }^{10}$. Esto, desde luego, no es un revival del convencimiento revolucionario que trazaba un itinerario histórico lineal para arribar a una utopía. Así lo demuestra la fuerte crítica que en la novela se hace a los fanatismos políticos, nacionalistas, militares y religiosos. No obstante, no se renuncia a la idea de modificar el rumbo, de imaginar que es posible una realidad diferente. Pero esta no debe lograrse por la vía armada, como lo expresa el personaje de Andrés Ramírez, quien contesta a la manida idea de que la violencia es la partera de la historia: "Algún día habrá que modificar la comprensión de esa constante histórica [...] No es posible seguir con la misma fórmula de los cambios violentos, sino avanzar hacia una especie de concordia universal" (65). De hecho, la historia de Andrés, un fotógrafo cuyas capturas remiten a las de Jesús Abad Colorado, da cuenta de

${ }^{10}$ El desencanto indica que no hay fe en el progreso, pero tampoco en la revolución; ya no se presagia la utopía y, cuando algo se avizora, es desgarradoramente apocalíptico (Franco 337). El capitalismo ha triunfado y es imposible revertir esa situación. Ante esta derrota, surgió en el cambio de siglo una literatura más individualista que la ya citada introducción de McOndo parece abrazar: "Los cuentos de $\mathrm{McOndo}$ se centran en realidades individuales y privadas [...] Pareciera, al releer estos cuentos, que estos escritores se preocuparan menos de su contingencia pública y estuvieran retirados desde hace tiempo a sus cuarteles personales" (13). 
algunas propuestas de acción desde el arte. Él retrata la violencia, pero sabe que lo esencial es priorizar las vidas de los que resisten $(225,311)$.

$\mathrm{Y}$ es que, para Andrés, son esas personas "vejadas, pero inviolables en su dignidad" (268) las que pueden encontrar la salida en medio del callejón de la violencia. Por eso, el profesor de Historia insiste en la necesidad de producir otros relatos que hablen desde los vencidos. Si leemos esto en clave ranceriana, notaríamos que, tal como sugiere el autor francés, la verdadera posibilidad dependería de que los sin-parte logren aparecer en las dinámicas de visibilidad que supone el reparto de lo sensible. Sin embargo, la obra se enfrenta aquí con sus propios límites. Se nos dice que es momento de hablar desde las víctimas, desde esas comunidades que han sido vejadas y dejadas de lado por el relato de la historia oficial. No obstante, poco de eso se ve en Los derrotados. Es verdad que, por momentos, esas víctimas son identificadas con la dignidad y son abanderadas de la defensa de la vida, como los habitantes de Bojayá, quienes, después de haber sido víctimas de hechos horribles, "se preguntan en coro, quiénes somos, y en coro se responden, somos civiles [...] La gente se pregunta con más fuerza, qué queremos, y en coro se responde, la vida" (235). Pero estos pasajes son los menos, y poco o nada sabemos de esas gentes, de sus subjetividades, de sus maneras de ver el mundo, de sus conocimientos propios ni de su relación con el entorno. Se nos dice que son ellos quienes han de abanderar el cambio y, a pesar de ello, casi nunca los vemos como seres con capacidad de agencia. Esto es muy diciente en el caso de las mujeres: en la obra se critica que la revolución sea una cosa masculina (33), pero qué poco protagonismo tienen ellas en esta novela en la que, en repetidas ocasiones, no pasan de ser objetos de deseo.

En realidad, la "propuesta" de la obra parte de otra base, directamente relacionada con el problema de la deshistorización y la mitificación del continente americano. Hemos visto hasta aquí cómo en la novela se construye una memoria por medio de la rehistorización de la naturaleza, de los crímenes contra ella, no solo en el contexto del conflicto armado, sino desde la Conquista. Pero la naturaleza se reivindica como algo más que un recurso de explotación. Y es que las plantas, a lo 
largo de la obra, trascienden su condición de objetos de estudio "racionales" para Caldas: son fuentes del hecho estético ["El botánico debe escribir primero sobre la belleza" (124)]; son enigmas inescrutables ["Sospecho que la búsqueda de un rasgo vegetal es de algún modo ilusoria, porque él cambia frecuentemente y no hay una forma definitiva de su apariencia" (121)]; son una amplitud que excede las fronteras políticas ["El Reino es una mano empuñada que va abriéndosele. Bordeando los ríos, subiendo los montes, bajando las hondanadas, atravesando los valles, viendo caer sobre los árboles una lluvia ecuménica, Caldas comprende para qué existe" (54)], y son, por último, fundamentales para la vida ["Es necio suponer que hay plantas menores. Todas son indispensables para la tierra. [...] Propagar la vida, ante la perentoria presencia de la muerte, es como las flores susurran su inteligencia"] (124-125). Ideas como las anteriores han sido expresadas, tal como se dice en el fragmento, en otros momentos de la historia del pensamiento. En la actualidad, se podrían destacar las investigaciones de Emanuele Coccia, quien apunta que "son las plantas las que, hace millones de años, han transformado el mundo produciendo las condiciones de posibilidad de la vida animal" (75) y, por tanto, aboga por una epistemología fundada en la vida vegetal. Así mismo, en la propuesta de Los derrotados, hay una encendida defensa de las plantas en boca de un hombre apasionado por las orquídeas que conversa con Santiago sobre el final de la novela: "Se habla de genocidios indígenas, de la trata de esclavos, de los exterminios de judíos, de cristianos, de musulmanes, de budistas. Otros se refieren a la aniquilación de las focas, las ballenas, los elefantes, las vacas. Pero ¿quién habla de la matanza continua de las orquídeas?" (304). Este profundo respeto hacia la vida (humana y vegetal), como he dicho en otro ensayo, es parte esencial del cosmopolitismo de Montoya, que se opone vehementemente a las guerras, a las fronteras y a las identidades nacionales (Saldarriaga Gutiérrez, Literatura, historia y antibelicismo). Cerrar con esto me parece necesario para apuntar otro rasgo que Los derrotados revela del giro rural: esta obra, a pesar de "volver" a temas y a espacios locales, no es regionalista: no se propone ser una "producción auténtica" de la "verdadera [...] literatura colombiana y latinoamericana" (Williams 19). Incluso, en el ámbito 
espacial, se acude a la multiterritorialidad: así como hay acciones que transcurren en pueblos recónditos de Antioquia o el Chocó, otras suceden en París o en alguna playa de Costa de Marfil. Y es que si bien, como decía antes, en la obra de Montoya se ha ido dejando de lado la extraterritorialidad, las búsquedas universales y cosmopolitas se mantienen ${ }^{11}$.

\section{Elástico de sombra y el territorio}

Aunque las dos novelas aquí estudiadas se pueden asociar al giro rural, es posible observar diferencias sustanciales entre una y otra. En contraste con la multiterritorialidad de Los derrotados, Elástico de sombra, de Juan Cárdenas, se sitúa específicamente en el Cauca para contar la historia de don Sando, un maestro de la esgrima de machete, y su discípulo Miguel, quienes buscan recuperar una olvidada técnica de este arte marcial. Igualmente, en términos políticos, esta novela presenta una propuesta más radical. En cierto pasaje de Los derrotados, Pedro formula una diatriba contra la "literatura funcional", a la que califica de "peligrosa" y acusa de "producir simplezas, cosas sin brillo, prosaísmo sentimental, güevonadas didácticas" (143). Reparos como esos no parecen tener importancia en Elástico de sombra, que desde su nota "liminar" manifiesta abiertamente su propósito: "Con este libro espero contribuir a la memoria y el presente de las luchas negras de toda América, además de ofrecer herramientas para el que sin duda es el proyecto más urgente de la cultura universal, a saber, la aniquilación definitiva del Hombre Blanco" (7).

Así mismo, mientras que Los derrotados busca reelaborar la relación con la naturaleza sin reparar demasiado en la manera en que las comunidades se han construido colectivamente a partir del entorno, Elástico de sombra utiliza como eje central de su propuesta la noción de territorio. "Nosotros no queremos tierra", dice

${ }^{11}$ Esta dualidad entre lo local y lo global es percibida en términos estéticos por Camilo Bogoya, quien afirma que Los derrotados hace "explícito el conflicto entre una realidad tremebunda que exige al escritor desarrollar una temática, tomar posición, traducir para los otros la hecatombe de la historia nacional, y una conciencia libre de cualquier dependencia, libre de cualquier sometimiento a valores que no sean estéticos o que se relacionen con una estética subjetiva e independiente" (70). 
en la novela la lideresa negra Francia Márquez, "queremos territorio". Esta aseveración la podríamos entender a la luz del trabajo del antropólogo colombiano Arturo Escobar, quien define el territorio como un espacio colectivo "donde hombres y mujeres, jóvenes y adultos, crean y recrean sus vidas. Es un espacio de vida donde se garantiza la supervivencia étnica, histórica y cultural” (32). Se traza de este modo un desplazamiento hacia la densidad simbólica de la comunidad negra del Cauca, desde la cual se construye memoria en Elástico de sombra. Esto significa adoptar un cambio de perspectiva, evidente en el pasaje en que Miguel camina por Popayán, esa ciudad “donde el turista pendejo ve callecitas pintorescas y arquitectura colonial", pero que para los negros "es sinónimo de opresión, de despojo [...] del latifundio esclavista de ayer y del latifundio esclavista de hoy" (87). Para la búsqueda de esa otra perspectiva, parece necesario renunciar a la voz propia. En Elástico de sombra también hay un trasunto ficcional del autor real: Cero, descrito en la novela como "un escribidor blanquito, así medio cafeconleche, que vivía con el hocico metido en cosas de negros" (11). Este personaje es relevante porque le permite a Cárdenas, más que un ejercicio de autoficción, uno de autoconciencia en el que reflexiona sobre la poética de la obra:

Quizá Cero no era la persona indicada para contar cosas de negros, quizá esa labor le correspondía a los propios negros [...] Igual, concluyó Miguel, su amigo no era ningún apropiador [...] sino más bien una especie de contrabandista $[\ldots]$ tratando de borrar las fronteras raciales que el hombre blanco inventó [...] Y aunque a veces tenía dudas sobre la legitimidad de sus actividades, Cero [...] se cagaba en todo ese complejo mecanismo de segregación y no permitía que le dijeran desde dónde hablar y cómo. (73)

Las incertidumbres y las convicciones contenidas en este fragmento no son gratuitas. Y es que, a diferencia de Los derrotados, en la que la voz de Pedro es siempre fuerte y se superpone a la de Caldas, la de Cero se apaga, se reduce - en una asociación de palabras nada gratuita - a cero, cuando el personaje es 
convertido en insecto y la narración recae, entonces, en los personajes negros del territorio $^{12}$. Son ellos quienes, a través de una prosa que recrea la oralidad de la zona, articulan su pasado, su presente y sus expectativas de futuro ${ }^{13}$.

Con respecto al pasado, es diciente que la narración eclosione por la voluntad de recuperar una técnica olvidada de la esgrima de machete. Pero la búsqueda no se limita a ello. Encontramos también pasajes en los que se rescata una memoria doble: la del pueblo negro en un sentido más general y la de los macheteros en particular. En el primer caso, aunque no se conjugan hilos narrativos de distintas épocas como en Los derrotados, sí se sitúa lo narrado en un contexto histórico más amplio y aludido en la nota "liminar": el de las luchas negras. Por eso, en un momento de la novela, don Sando se identifica con las víctimas de una violencia antiquísima cuando:

[Ve] desfilar ante sus ojos [...] una historia de siglos y siglos: sus antepasados, los que sobrevivieron a la travesía del infame barco donde los trajeron apeñuscados [...] difícil llevar la cuenta de los vivos, mucho más difícil saber cuántos no consiguieron superar la prueba y fueron arrojados por la borda, pero que fuimos muchos nadie lo duda, millones y millones de personas [...] Luego nos vendieron en mercados, en plazas públicas, en subastas, como animales de carga y, así, de a poquitos, a punta de garrote, perrero, castigo, socavón y latigazo, a muchos nos fueron quitando el idioma, los recuerdos. (46-47)

\footnotetext{
${ }^{12}$ Catalina Quesada-Gómez ha señalado que la literatura de Cárdenas busca incluir "lo negro" en el proyecto nacional (125). Para ello, explica la investigadora, el autor pone en práctica estrategias de "ennegrecimiento" que, sin embargo, considero que pueden leerse de manera más productiva si se toma como punto de partida el abandono de "lo blanco".

${ }^{13}$ Esta no es una operación meramente retórica. Un lenguaje distinto acarrea un pensar distinto: una comprensión del mundo que, en la novela, dista del frío y abstracto racionalismo para situarse desde una sabiduría vital y material. No en vano, "en el idioma olvidado de los tatarabuelos", la palabra timbu significa pensamiento y, al mismo tiempo, sabor, sensación tan concreta como misteriosa e incomunicable (35). Este tipo de pasajes confrontan, directamente, la razón moderna: a la luz clara que precisa el ojo occidental, se contrapone la esgrima de machete, hecha de sombras y oscuridad; a la abstracción de la lógica, se sitúa el cuerpo, sustento material del arte marcial, pero también "lugar" concreto que porta las marcas del pasado y las fuerzas del conocimiento y la memoria (47).
} 
Esa violencia, de raíces profundas, ha devenido estructural y global: "Los descendientes de quienes esclavizaron a nuestros tatarabuelos hace cuatro siglos, hoy son agentes al servicio de una máquina global de muerte” (65), dice el personaje de Francia Márquez, lo que legitima y potencia los reclamos de la comunidad negra, que complejiza el tiempo histórico al vincular lo ancestral y lo actual. Los macheteros son quienes ofrecen la puerta de entrada a esta cosmovisión $\mathrm{y}$, por eso, también se reivindica su memoria particular. Esta está permeada por mitos y leyendas de los que forman parte personajes que entran en el universo de la novela, como las brujas, el Viento, el Duende y el diablo (El-Que-Ya-Sabemos). Así mismo, hay pasajes en la novela que nos cuentan la historia de los macheteros desde la Guerra de los Mil Días. De esta manera, sabemos que en ese conflicto estuvieron al mando del general Avelino Rosas, que fueron fundamentales en la Guerra contra el Perú hacia 1930, que se alzaron en armas el 9 de abril de 1948, que fueron traicionados por el Partido Liberal y que, posteriormente, fueron desprestigiados, perseguidos y casi arrojados a la clandestinidad. En los apartados en los que se nos cuenta este relato, también se explica el significado de recuperarlo: resistirse al olvido para "mantener viva la llama de una historia". "Al final", le dice a Miguel la maestra Fidelia, una de las personas que lidera la minga, “¿qué es esa resistencia de la que tanto hablamos sino una pelea contra la muerte y el olvido sistemático, contra el olvido impuesto desde arriba?". Y concluye: "Nosotras resistimos porque nuestra resistencia cava un hueco en la piedra dura de la ley, para que la ley se amolde al cuerpo del pueblo" (80).

De este modo, la potencia de la memoria no se apaga en el presente: sigue combativa, y no en un sentido abstracto, sino material; por ello, la novela comporta también una perspectiva crítica sobre hechos puntuales de la actualidad del país que hacen ambiguo el pacto de lectura. Hay, incluso, pasajes que podrían leerse como consignas que operan, sin modificación alguna, en la "realidad" política nacional: "No más asesinatos de líderes, no más incumplimiento de los compromisos, no más persecución política, no más estigmatización de los defensores del territorio, no 
más" (64), exclama un personaje antes de unirse a la minga indígena. En otro pasaje, sobre los resultados de los últimos comicios presidenciales, en los que fue elegido el candidato del uribismo, Iván Duque, se dice: "Se sabía lo que iba a pasar después de las elecciones [...]. Y pasó. Volvió la guerra" (44).

Pero, más importante que esas críticas, es la manera en que se retrata a los líderes sociales, principales víctimas de la violencia posterior a la firma de los Acuerdos de Paz. Ellos son homenajeados en la novela, pero no a partir del exterminio del que han sido objeto, sino de su labor política y su defensa de los territorios: Feliciano Valencia, Clemencia Carabalí, Aída Quilcué y Francia Márquez aparecen con sus nombres propios y son calificados como "la vanguardia de los movimientos sociales del Cauca" (74). Esto último es esencial, pues la novela se resiste a representar el conflicto armado; en cambio, prefiere hacer visibles los conflictos ideológicos que los discursos demasiado centrados en la violencia suelen soslayar. Tal es el grado de crítica a la representación del horror que, cuando Sando, Miguel y Cero encuentran en un cruce de caminos los cadáveres de un hombre y una mujer jóvenes, asesinados en el contexto de la violencia política, enseguida se nos cuenta que "ninguno era capaz de decir nada". Y se concluye: "Hay cosas que no admiten comentario" (43). Este silencio es significativo: en lugar de un duelo enfocado en lamentar la violencia, las vejaciones y la derrota, Elástico de sombra se encauza hacia la vida de la comunidad, sus luchas y sus esperanzas de futuro.

De esta manera, si en Los derrotados estamos ante la pregunta por la naturaleza americana, en Elástico de sombra volvemos a otro tema de no menos envergadura: el choque entre tradición y modernidad. Esto es esencial para el relato de memoria desde las comunidades negras e indígenas que aparecen en la obra, cuya identidad, a pesar de estar vinculada a la tradición, no se agota en el pasado, sino que es fruto del proceso histórico. Esto se resalta en la apropiación que hacen estas comunidades de tecnologías como internet, WhatsApp (escrito "guasap" en la novela) y YouTube, además de drones que el consejo regional indígena emplea para su defensa y que, en un gesto de alto sincretismo, arrojan sobre los policías una sustancia ácida, paralizante y pegajosa elaborada con plantas. No son baladíes 
estos elementos, pues reivindican la potencia histórica y política de estos grupos. Así lo expresa el personaje de don Floro, un indígena nasa: "Los blancoides de las ciudades se creen que los indios somos cualquier lagaña'e mico. Y nosotros estamos preparados para todos los cambios porque venimos de muy atrás. Sabemos usar todos los recursos, sabemos dar la lucha en todos los frentes" (82).

Las convicciones que empujan esas luchas son expresadas con claridad en el que acaso sea el punto más alto de la novela: el discurso que pronuncia la líder negra Francia Márquez, en el cual se sintetizan las cuestiones más relevantes para mi lectura de la novela. Hay, en primer lugar, una reivindicación de la relación comunitaria con el entorno, donde, según Márquez, "al menos desde 1632, nuestros ancestros consiguieron asentarse [...] para barequear oro en el río y trabajar la tierra, cuidando el agua, el bosque, la montaña" (64). Sobre esa base, se cristaliza el citado tránsito de la tierra al territorio: "No somos propietarios", dice Márquez, "somos los cuidadores, los guardianes de estas tierras" (65). Y, a continuación, vemos cómo este relato local y pretérito no significa en absoluto dejar de lado el futuro global. Desde ese territorio específico, Márquez explica que el fin último es combatir la máquina global de muerte mencionada unas páginas atrás para disputarle el porvenir:

Nosotros somos todo lo contrario $[\ldots]$ producimos y cuidamos la vida $[\ldots]$ cuidamos el futuro. Y no sólo el futuro de nosotros como comunidad [...] cuidamos el futuro de todos, hasta el futuro de ellos y el de los hijos de ellos. Porque esa máquina automática de muerte está acabando con todo el planeta [...] Esto ya no es sólo una lucha por la propiedad de la tierra, es una lucha por la defensa del planeta en su totalidad. (65)

Vemos, entonces, un vínculo a un territorio concreto en la vía que, como ya señalé, apunta Gisela Heffes sobre la renovada importancia de la noción de lugar. Sin embargo, esto no implica que la novela esté gobernada por una actitud reaccionaria. Por el contrario, si Cárdenas sitúa sus obras en este tipo de espacios 
es porque allí reconoce fuerzas políticas y estéticas que no se retraen, sino que se expanden para confrontar el sistema global dominante. He aquí otro modo de ubicarse en la tensión local-global y de hacerla productiva: no logrando que un lugar pueda confundirse con cualquier otro, ni defendiendo a ultranza los valores locales y tradicionales por encima de los globales y modernos, sino hallando en un territorio concreto, material, vejado, una capacidad de agencia para pensar y acaso transformar lo global.

También vale la pena señalar que, si en Los derrotados podemos criticar la poca visibilidad de las mujeres, en Elástico de sombra ellas desempeñan un papel fundamental en las posibilidades a futuro. Un ejemplo es, por supuesto, el liderazgo de Francia Márquez, pero también es preciso destacar que es un grupo de mujeres macheteras el que porta el secreto de la técnica perdida. Esto se debe a una postura que contradice las directrices académicas de la lengua española: el Duende, que tenía prohibido enseñar a los hombres el secreto de la esgrima, se aprovecha de la insuficiencia universal de ese significante para revelarles la técnica a las mujeres. Otro aspecto a resaltar en cuanto a las posibilidades de futuro: aunque la literatura de Cárdenas pueda considerarse como "comprometida" en la medida en que, como se lee en la nota "liminar", espera contribuir a luchas políticas del mundo real, esto no significa que su apuesta se funde en la certeza de la llegada a una utopía. De hecho, en otro fragmento muy diciente sobre la poética de la novela, se lee que "la poesía no rompe el misterio, sino que le da forma". El misterio, como el diablo, es otro motivo que se repite en las obras de Cárdenas, y que por momentos se puede identificar, por ejemplo, con los mecanismos estructurales que son la raíz última de la violencia y la injusticia. No sin motivo, el mercado se asemeja a una "mano invisible blanca que mueve todas las manos pardas" y se juzga como la "brujería más eficaz" que haya sido inventada (46). Sin embargo, la cuestión se intuye mucho más honda, y tiene que ver con el misterio de la experiencia y la incertidumbre de lo que pueda suceder en el porvenir. Pero este misterio no es una razón para el temor ni para la inacción. Después de todo, según se dice en la obra, "un esclavo que no hace nada es todavía más esclavo" (20). Por ello, el proyecto político que se 
reivindica en la obra (y que se puede tomar también como literario, al tratarse de palabras dichas por el escritor Cero) celebra la acción, aunque esta carezca de un rumbo fijo: "Yo tampoco tengo ningún temor de que nuestro viaje no tenga un propósito muy concreto. Los fantasmas deambulan sin rumbo fijo, atravesando muros por el puro placer de atravesarlos" (52).

\section{Apuntes finales}

El giro rural no es la principal manifestación estética de la literatura reciente, pero es una vertiente en la que podemos encontrar hallazgos valiosos. Desde luego, no todas las obras que componen este conjunto comparten idénticos rasgos. Sin embargo, quiero cerrar este texto apuntando algunas claves generales del giro rural en la literatura colombiana. Como he dicho en la introducción, aunque hay excepciones importantes, la mayor parte de novelas colombianas de los últimos años que se sitúan en el campo se refieren, de una $u$ otra manera, al conflicto armado. Esto representa un cambio en la mirada al incorporar elementos que habían recibido menos atención en las narraciones de la violencia en Colombia, como el daño a los ecosistemas y el despojo de territorios campesinos y ancestrales. La relevancia de esos aspectos proviene, en parte, del contraste que ofrecen con el discurso de la "narcocultura", en el cual la violencia es un producto desideologizado de la codicia neoliberal y del deseo de ascenso social. En el caso de algunas obras del giro rural, por el contrario, se legitiman los reclamos políticos de diferentes comunidades y se redescubren las raíces ideológicas del conflicto, lo que reactiva la potencia de la memoria sin ceder a la parálisis melancólica o a la tentación del consenso. En este sentido, el campo no se define únicamente por la violencia o el atraso. Por supuesto, se alude a su desconexión con la ciudad por la histórica fragmentación geográfica y social de Colombia; sin embargo, se reconoce que en esos territorios hay capacidades de agencia política, económica, social, ambiental y artística. Frente a esto, considero necesario anotar que sería un error equiparar el

giro rural con el retorno de una literatura regionalista que aboga por la pureza de las comunidades étnicas, que imagina el campo como una arcadia pura y deseable, 
o que se resiste a cualquier tipo de progreso. En las obras analizadas, se ha mostrado que los alcances de estas propuestas buscan exceder el espacio local e incidir en lo global.

Quiero señalar también que el vínculo entre ética y estética es primordial para aproximarse a la literatura reciente en Colombia y América Latina. En un artículo publicado por la Revista Arcadia, la escritora Andrea Salgado aseguraba que una buena parte de la narrativa colombiana de los últimos años está consolidando apuestas estéticas que no son ajenas a las preocupaciones políticas. Esta observación, si bien puede tener matices locales, indudablemente se entronca con una tendencia más amplia. No sin motivo, Francisca Noguerol emplea la noción de "giro ético" para apuntar un rasgo definitorio de la literatura en lengua española de la última década: el propósito de hablar desde los vencidos, de sacudir la indiferencia de los lectores y de dinamitar el consenso sobre el estado actual de las cosas en el orden global, sin nunca dejar de lado la innovación formal (21). Desde luego, no toda la producción literaria reciente se ajusta —ni ambiciona ajustarsea estos postulados. Por eso, Noguerol califica de "subversivas" aquellas propuestas que consideran el experimento estético como una necesidad ética, es decir, como la principal manera de fracturar las formas hegemónicas del lenguaje oficial. Precisamente, hemos visto que, a partir de elecciones estéticas como la narrativa histórica, en el caso de Montoya, o del empleo de otras manifestaciones de la lengua, como en Cárdenas, es posible (y acaso necesario) construir relatos con el propósito de reordenar el espacio común, principalmente desde aquellas partes sinparte de las que habla Rancière, que tienen el poder de mantener el desacuerdo para que la memoria sea más que un ejercicio narcisista y políticamente estéril. En este sentido, el giro rural implica no solo salir de la ciudad, sino también un poco de nosotros mismos para reconocer en los territorios y las subjetividades más vejadas del conflicto armado las potencias necesarias para construir posibilidades mejores. ¿Por qué es necesario esto? Pienso ahora en las palabras con las que Hobsbawm concluía la introducción a su monumental Historia del siglo XX: "El viejo siglo no 
ha terminado bien" (26), sentenciaba el historiador. Después de dos décadas, hay que decirlo, tampoco parece que este marche sobre ruedas.

\section{Bibliografía}

Agamben, Giorgio. “QQué es lo contemporáneo?”. (2008). https://19bienal.fundacionpaiz.org.gt/wpcontent/uploads/2014/02/agamben-que-es-lo-contemporaneo.pdf. $10 \mathrm{de}$ julio de 2020.

Aínsa, Fernando. "Palabras nómadas: los nuevos centros de la periferia". Alpha 30 (2010): 55-78.

Assmann, Aleida. "Memory, individual and collective". The Oxford Handbook of Contextual Political Analysis. Robert E. Goodin y Charles Tilly, editores. Nueva York: Oxford University Press, 2006. 210-224.

Avelar, Idelber. Alegorías de la derrota: la ficción posdictatorial y el trabajo del duelo. Santiago de Chile: Universidad ARCIS, 2000.

Bogoya, Camilo. "La literatura colombiana: ¿un problema de fronteras?". América sin Nombre 24 (2019): 63-71.

Cárdenas, Juan. Elástico de sombra. Ciudad de México-Madrid: Editorial Sexto Piso, 2019.

Chávez, Ricardo y otros. Crack. Instrucciones de uso. México D. F.: Random House Mondadori, 2004.

Coccia, Emanuele. La vida de las plantas. Buenos Aires: Miño y Dávila, 2017.

Fuguet, Alberto y Gómez, Sergio, editores. McOndo. Barcelona: Grijalbo Mondadori, 1996.

De Leone, Lucía. "Imaginaciones rurales argentinas: el campo como zona de cruce en expresiones artísticas contemporáneas". Cuadernos de Literatura XX/40 (2016): 181-203.

Erll, Astrid. Memoria colectiva y culturas del recuerdo. Bogotá: Ediciones Uniandes, 2012.

Escobar, Arturo. "Territorios de diferencia: la ontología política de los 'derechos al territorio"”. Cuadernos de Antropología Social 41 (2015): 25-38

Franco, Jean. Decadencia y caída de la ciudad letrada. Barcelona: Debate, 2003.

Freud, Sigmund. "Duelo y melancolía". Obras completas. Volumen XIV. James Strachey, editor. Buenos Aires: Amorrortu Editores, 2003. 235-256.

Halbwachs, Maurice. La memoria colectiva. Zaragoza: Prensas Universitarias de Zaragoza, 2004.

Heffes, Gisela. "Introducción. Para una ecocrítica latinoamericana: entre la postulación de un ecocentrismocrítico y la crítica a un antropocentrismo 
hegemónico". Revista de Crítica Literaria Latinoamericana 40/79 (2014): 11-34.

Hobsbawm, Eric. Historia del siglo XX. Barcelona: Crítica, 2000.

Marcone, Jorge. "De retorno a lo natural: La serpiente de oro, la "novela de la selva' y la crítica ecológica". Hispania 81/2 (1998): 299-308.

Matijasevic, María Teresa y Ruiz, Alexander. "La construcción social de lo rural". Revista Latinoamericana de Metodología de la Investigación Social 5/3 (2013): 24-41.

Monsiváis, Carlos. Viento rojo. Diez historias del narco en México. México: Plaza y Janés, 2004.

Mate, Reyes. La herencia del olvido. Madrid: Errata Naturae Editores, 2008.

Montoya, Pablo. Los derrotados. Medellín: Sílaba Editores, 2019.

Mora, Vicente Luis. "Líneas de fuga neorrurales de la literatura española contemporánea". Tropelías. Revista de Teoría de la Literatura y Literatura Comparada, número extraordinario 4 (2018): 198-221.

Noguerol, Francisca. "Narrar sin fronteras". Entre lo local y lo global: la narrativa latinoamericana en el cambio de siglo (1990-2006). Jesús Montoya y Ángel Esteban, editores. Madrid-Frankfurt: IberoamericanaVervuert, 2008. 19-33.

. "Contra el Capitaloceno: escrituras subversivas en el siglo XXI". Faires d'écriture: quand la littérature pense la politique. Marta Waldegaray, editora. Reims: EPURE, 2020. 77-96.

Ospina, María. "Natural Plots: The Rural Turn in Contemporary Colombian Cinema". Territories of Conflict: Traversing Colombia through Cultural Studies. Andrea Fanta Castro, Alejandro Herrero-Olaizola y Chloe Rutter-Jensen, editores. Nueva York: Boydell \& Brewer, University of Rochester Press, 2017. 248-266.

Prieto, Julio. La escritura errante. Ilegibilidad y políticas del estilo en Latinoamérica. Madrid-Frankfurt: Iberoamericana-Vervuert, 2016.

Quesada-Gómez, Catalina. "La afrocolombianidad en el siglo XXI: estrategias de ennegrecimiento y aproximaciones de algunos autores 'no blancos' a la cuestión racial". Literatura y globalización: Latinoamérica en el nuevo milenio. Eva Valero y Oswaldo Estrada, editores. Barcelona-Santa Fe: Anthropos Editorial-Universidad Nacional del Litoral, 2019. 113-126.

Rancière, Jacques. El desacuerdo. Política y filosofía. Buenos Aires: Ediciones Nueva Visión, 1996.

. El reparto de lo sensible. Estética y política. Buenos Aires: Prometeo libros, 2014. . "El giro ético de la estética y de la política". Disenso. Ensayos sobre estética y política. Steven Corcoran, editor. México: Fondo de Cultura Económica, 2019. 231-251.

Richard, Nelly. Fracturas de la memoria. Arte y pensamiento crítico. Argentina: Siglo XXI, 2007. 
Saldarriaga Gutiérrez, Sebastián. "La búsqueda posnacional: nación y cosmopolitismo en Adiós a los próceres". Estudios de Literatura Colombiana 41 (2017): 49-62.

. "Literatura, historia y antibelicismo en Los derrotados, de Pablo Montoya." Mitologías hoy 16 (2017): 287-296.

Salgado, Andrea. "Historias imperfectas: la estética (y política) de la literatura colombiana contemporánea". Arcadia (2019). https://www.revistaarcadia.com/periodismo-cultural---revistaarcadia/articulo/historias-imperfectas-la-estetica-y-politica-de-laliteratura-colombiana-contemporanea/. 20 de junio de 2020.

Williams, Raymond. El campo y la ciudad. Buenos Aires-Barcelona-México: Paidós, 2001.

Williams, Raymond Leslie. "Tomás Carrasquilla, Mario Vargas Llosa y el regionalismo del siglo XXI”. Lingüistica y Literatura 61 (2012). 19-26. 